\title{
MARÍA (1867) DE JORGE ISAACS (1837-1895) Y EL PROYECTO CULTURAL DE NACIÓN MEXICANA. El CASO DE IGNACIO MANUEL Altamirano (1834-1893)*
}

Fecha de recepción: 7 de marzo de 2014

Fecha de aprobación: 27 de mayo de 2014

\section{Resumen}

El objeto del presente estudio es el análisis de la recepción de María de Jorge Isaacs en el contexto mexicano de finales del siglo XIX, en aras de evidenciar la importancia que esta novela tuvo en el proyecto cultural de nación mexicana, llevado a cabo por los intelectuales liberales durante la Restauración, en especial por Ignacio Manuel Altamirano.

Palabras clave: Altamirano, Ignacio Manuel; Isaacs, Jorge; Literatura XIX; México XIX; Liberalismo; Nación.

* Artículo de investigación derivado del proyecto El crítico de lo cultural en las publicaciones periódicas de 1900 a 1960. Una forma histórica del intelectual colombiano (2013-2016), ejecutado con recursos de la Convocatoria de proyectos de investigación de Ciencias Sociales, Humanidades y Artes (2012), financiada por el Comité para el Desarrollo de la Investigación (CODI) de la Universidad de Antioquia; también se inscribe en el marco de la Estrategia de sostenibilidad para grupos de investigación CODI 2013-2014. La indagación bio-bibliográfica se realizó en los archivos del Instituto Iberoamericano de Berlín (IBI), en el marco de la Beca para estancias de investigación, concedida al autor del artículo en el 2011 por el Servicio Alemán de Intercambio Académico (DAAD).

Citar: Bedoya Sánchez, G. (julio - diciembre de 2014). María (1867) de Jorge Isaacs (1837-1895) y el proyecto cultural de nación mexicana. El caso de Ignacio Manuel Altamirano (1834-1893). La Palabra (25), 17-29

\section{Gustavo Adolfo Bedoya Sánchez}

Universidad de Antioquia, Colombia

gustavoadolfo00@yahoo.com

Profesor de la Universidad de Antioquia, Medellín, Colombia. Candidato a Doctor en Historia de la Universidad Nacional de Colombia, sede Medellín. Magíster en Literatura Colombiana de la Universidad de Antioquia. Miembro del Grupo de Investigación Colombia: tradiciones de la palabra (CTP) de la misma universidad. Más información acerca del grupo, en: http://ihlc.udea.edu.co/ Miembro de la Red Colombiana de Investigadores en Publicaciones Periódicas: https://sites. google.com/site/redcolombianapren$\mathrm{sa} /$. 
MARÍA (1867) BY Jorge IsAaCs (1837-1895)

AND THE CULTURAL PROJECT OF NATION MEXICANA. The Case of Ignacio Manuel Altamirano (1834-1893)

\section{Abstract}

The purpose of this study is to analyze the reception of María by Jorge Isaacs in the Mexican context of the late nineteenth century, in order to demonstrate the importance of this novel had on the Mexican national cultural project, carried out by intellectuals liberals during the "Restauración", in particular by Ignacio Manuel Altamirano.

Key words: Altamirano, Ignacio Manuel; Issacs, Jorge; Literature XIX; México XIX, Liberalism; Nation.

\section{MARÍA (1867) DE JORGE IsAACS (1837-1895): SA RÉCEPTION DANS LA PRESSE LITTÉRAIRE MEXICAINE PENDANT LA DEUXIÈME MOITIÉ DU XIXÈME SIÈCle. LE CA D'IGNACIO MANUEL Altamirano (1834-1893)}

\section{Résumé}

L'objet de cette étude est l'analyse de la réception de Maria, de Jorge Isaacs, dans la presse littéraire mexicaine au début et à la fin du XIXème siècle, sur l'autel de mettre en évidence l'importance que ce roman-là a eu dans le projet culturel de nation mexicaine; celui-ci, mené à bien par les intellectuels libéraux pendant la Restauration, en particulier par Ignacio Manuel Altamirano.

Mots clés: Libéralisme, Littérature, Réception, Journalisme, María 


\section{Introducción: María de Jorge Isaacs, una obra ejemplar}

La novela de Jorge Isaacs ha sido considerada por la historia literaria colombiana, en general, como la obra de mayor importancia en el contexto nacional (Rincón, 2007; Toro y Vallejo, 2007). En términos historiográficos ella es el momento cúspide de lo literario, de allí que el resto de obras sean siempre comparadas, dadas sus afinidades o diferencias, con María. En la historia literaria continental, la novela de Isaacs es considerada como una obra de valor canónico, emparentada con el romanticismo español, incluso, en muchos casos se ha argumentado que ella es el culmen de dicho movimiento literario en América hispánica (Henríquez, 1994, pp. 152-153)..$^{1}$ Es así como Seymour Menton establece la existencia de cuatro "planetas" narrativos, es decir, cuatro novelas en la historia literaria colombiana, a las cuales les orbitan una serie de novelas "satélites". La primera novela relevante es, justamente, la obra de Isaacs:

\begin{abstract}
Si María ha sobrevivido más de un siglo tanto entre los lectores adolescentes como entre los críticos más eruditos, no es por casualidad. La novela de Isaacs, aclamada como obra maestra del romanticismo americano $y$ progenitora de novelas sentimentales en casi todas las naciones hispanoamericanas, se mantiene hoy día por la clara conciencia artística con que Isaacs la concibió y la elaboró (Menton, 1978, p. 15) ${ }^{2}$.
\end{abstract}

Muestra del afecto que la obra ha ganado a lo largo de los años son sus numerosas ediciones, así como las diversas traducciones y diferentes adaptaciones que se han hecho de ella para el teatro, la radio, el cine y la televisión, y el ingente número de reseñas, notas, artículos, ensayos y tesis que el estudio de la obra ha coleccionado, tanto dentro como fuera de Colombia, en español o en otra lengua ${ }^{3}$. Véase el número de eventos: congresos, coloquios y seminarios que llevan como eje temático la vida y obra del autor, y el alto número y la diversidad de páginas de Internet que existen sobre el argumento de la novela, su autor, e incluso sobre sus personajes.
Es de anotar que la positiva recepción de la obra inició el mismo año de su publicación, 1867, con una primera edición de 800 ejemplares emitidos en principio para la capital de la República colombiana, la cual por aquellos años no contaba con más de 50.000 habitantes. La gran mayoría de ellos analfabetas. Asimismo, la minoría lectora no estaba interesada en leer literatura o cualquier otro tipo de documento. La segunda edición apareció en 1869 y, según Álvaro Pineda Botero, al finalizar el siglo XIX la obra contaba con un promedio de treinta ediciones (1999, p. 199), una cifra de suma importancia si tenemos en cuenta que en general, las obras literarias nacionales, en la segunda mitad del siglo XIX, no alcanzaban una segunda edición.

Ahora bien, la positiva recepción de María también se puede evidenciar por fuera de las fronteras colombianas.

De esta manera, las presentes páginas intentan exponer, en líneas generales, la acogida que la obra recibió por parte de un grupo de autores

1 La bibliografía crítica que ha coleccionado la novela es tal que nos parece ilógico reproducirla en estas página, de ahí que remitamos al trabajo de Gustavo Mejía en la edición de María de la Biblioteca Ayacucho (Isaacs, 1978).

2 A María le siguen en importancia, según los argumentos de Menton: Frutos de mi tierra (1896) de Carrasquilla (1858-1940), La Vorágine (1924) de Rivera (1889-1928) y Cien años de soledad (1967) de García Márquez (1927-): “Además de los cuatro planetas, Colombia cuenta con varios satélites, o sea novelas de menor magnitud que sin embargo merecen leerse y estudiarse por sus propios valores intrínsecos y por la posibilidad que ofrecen de descubrir las imperfecciones o debilidades que les han impedido alcanzar la misma categoría de las cuatro grandes" (p. 6).

3 Es de anotar que, tal como expone Alzate, "la historia de las relaciones entre el cine y la literatura colombiana", por ejemplo, se inician en México con la adaptación de la obra de Isaacs, hecha en 1918 por Rafael Bermúdez Zataraín: "una de las películas fundacionales del cine argumental de ese país y de la que apenas se conservan más noticias que el hecho mismo de su realización” (2012, p. 34). 
mexicanos, todos ellos liberales, durante la segunda mitad del siglo XIX, en el periodo conocido históricamente como República Restaurada o Restauración ${ }^{4}$. Nos centramos en el caso del intelectual Ignacio Manuel Altamirano y su grupo de letrados, en aras de exponer el uso que le dieron a la obra como caso a imitar, todo ello dentro de sus proyectos culturales civilistas liberales.

\section{Metodología: recepción} y estudio histórico de las literaturas

Tal como lo apuntó en 1967 Hans Robert Jauss (2000), el estudio histórico de las literaturas se ha centrado, con demasiada frecuencia, en el autor de la obra o en el mismo objeto literario. Cuando sucede lo primero las historias literarias, y también los textos críticos, corren el riesgo de desembocar en la semblanza biográfica, similar a las hagiografías (en la disciplina histórica ha sido usual elevar la vida de los próceres a la altura de los santos y semidioses); y cuando sucede lo segundo se corre el riesgo de restringir el análisis al estudio meramente estructural que ahoga la interpretación literaria en una serie de fórmulas abstractas, que finalmente dicen mucho acerca de sí mismas pero poco acerca del objeto literario estudiado.

Asimismo, en algunas ocasiones el análisis de la obra se limita a su aspecto anecdótico, lo que en teoría se ha denominado contenido, estableciendo en el peor de los casos relaciones directas y gratuitas de la obra con la vida del autor o del lector. En contraposición, Jauss establece la importancia de estudiar el fenómeno literario desde la recepción, ya que la obra literaria existe como tal en el momento en que es "activada" por el proceso lector, y no en el momento de la escritura, o cuando descansa pasivamente en el anaquel de la biblioteca:

\begin{abstract}
La relación entre la literatura y los lectores tiene implicaciones tanto estéticas como históricas. La implicación estética consiste en que la recepción primaria de una obra por el lector supone ya una comprobación del valor estético por comparación con obras ya leídas. La implicación histórica se hace visible en el hecho de que la comprensión de los primeros lectores prosigue $\mathrm{y}$ puede enriquecerse de generación en generación en una serie de recepciones, lo cual supone también una decisión acerca de la importancia histórica de una obra y hace visible su categoría histórica (Jauss, 2000, p. 159).
\end{abstract}

No se puede obviar tampoco que el análisis de la recep- ción permite el estudio de la obra en el contexto social que la produce y las características culturales que posibilitan su lectura, aspectos que regularmente son desconocidos u obviados en el análisis crítico e histórico de la literatura. Esta lectura que trasciende el análisis interno de la obra nos permitirá registrar el uso que hicieron de la novela los mexicanos liberales de la segunda mitad del siglo XIX. Esta recepción, como ya se verá, se restringió (en el mayor número de casos) a textos producidos para la prensa literaria (quizás, la mayor materialidad de lo literario de la época). La idea es marcar los momentos claves de esa recepción, pero sobre todo, leer entre líneas lo que la novela representó para los jóvenes letrados alrededor de los lineamientos culturales de Ignacio Manuel Altamirano, en otras palabras: la manera en que este grupo intelectual recibió la novela y la adaptó al discurso liberal de la época.

\section{Resultados: María en México}

La recepción de la obra de Isaacs abarcó diferentes países del continente y México no fue la excepción. Según lo hallado podemos argumentar que la inmediata recepción que María recibió en la capital mexicana ha sido una de las más impor-

4 Es de anotar que si bien la obra también fue recepcionada por la oposición conservadora mexicana de finales del siglo XIX, este trabajo se limita -ante la profusión de fuentes y por cuestiones metodológicas- a estudiar el caso de los liberales. 
tantes muestras del significado de la obra a nivel hispanoamericano, solo dos años después de publicada la novela en Colombia, México ya tenía noticia de ella, tal como expondremos.

Antes es necesario indicar que dadas las dificultades técnicas que en la época existían para reproducir materiales impresos, en formato libro, la prensa periódica contó con mayor efectividad, de allí que las primeras noticias que tengamos de la recepción de María descansen en estos medios y no en libros de crítica, propiamente hablando ${ }^{5}$. También es necesario tener presente otra dificultad, la relacionada con las comunicaciones y vías de acceso entre los países de América, así como entre las ciudades de un mismo país. Estos viajes se alargaban durante días enteros, incluso semanas. Además, la mayoría de estas travesías re presentaban un alto riesgo físico para los viajeros, eran verdaderas travesías dignas de toda una aventura; por ejemplo, para salir de la capital colombiana, a finales del siglo XIX, hasta la ciudad portuaria de Barranquilla, se debía emprender un viaje que podía llegar a durar hasta catorce días. ${ }^{6}$

Estas dos realidades: la dificultad material de la publicación y el peligro de las comunicaciones entre las diferentes capitales, provocaron que México recibiera, por primera vez, la obra del colombiano en formato folletín, exactamente gracias al papel desempeñado por el señor Vicente García Torres (1811-1894) en su diario El Monitor Republicano, diario que publicó por entregas semanales la obra literaria de Isaacs ${ }^{7}$.

La publicación de la novela en este diario pasó desapercibida para los intelectuales de la época, con la excepción del mismo García Torres que la promocionaba, tímidamente, en las mismas páginas de su publicación, tal como lo hacía con las otras muestras literarias allí editadas. La situación cambió drásticamente cuando las señoras de la capital, gracias al comentario diario, al cuchicheo y a los diálogos del día a día llamaron la atención sobre la obra contagiando a sus vecinas, sus amigas $\mathrm{y}$ al personal del llamado "servicio doméstico". Tanto fue así que la primera noticia que el escritor Ignacio Manuel Altamirano recibió acerca de la obra provenía de las observaciones de una amiga suya, quien le recomendó la lectura de la novela porque en ella se describía con "gran precisión" y "estilo" las costumbres del país que ella había tenido la ocasión de visitar, el cual se le parecía tanto a su México. En principio Altamirano no confió en el gusto de la mujer, así que no leyó el folletín, pero luego un amigo suyo, el distinguido poeta y crítico literario, Doctor Manuel Peredo (1830-1890), un "literato de mucho talento" como lo indica el mismo Altamirano, le advirtió la importancia de la obra. Altamirano empezó a leer el ejemplar del folletín que le

5 Un libro, además de costoso, era un objeto que por lo regular terminaba en la biblioteca personal de alguien (y en algunas ocasiones en las manos de los conocidos del dueño, gracias al tradicional préstamo entre amigos). En comparación, la publicación periódica, por sus relativos costos, transitaba activamente entre lectores, ya fuera que pasara de mano en mano, o por su lectura en voz alta para la escucha de otras personas en los cafés, las tertulias y las reuniones informales. Asimismo, en ocasiones, el periódico era fijado en las paredes de lugares públicos para la lectura de varias personas de manera simultánea (Chartier, 1994).

6 Primero se tomaba un tren hasta el municipio de Facatativá, lo cual representaba solamente los primeros 40 kilómetros de viaje, luego se debía viajar, incómodamente, en caballo y mulas de carga, hasta el municipio de Honda, lo que representaba cuatro días enteros, en los que se debía tomar descanso en cuatro lugares específicos. Una vez en Honda se tomaba un barco que viajaba por el río Magdalena hasta la costa Caribe, más o menos durante ocho o nueve días, bajo un sol abrasador. Por último, viajar desde la costa hasta, por ejemplo, el Antiguo Continente, un trayecto recurrente en aquella época, podía tomar un poco más de quince días (En aras de constatar esta información se puede leer las memorias y libros de viaje de la época, o la reconstrucción que Vallejo hace de los viajes de José Asunción Silva en la biografía Almas en pena Chapolas negras, 1995).

7 Este diario, subtitulado: "Diario de política, artes, industria, comercio, modas, literatura, teatros, variedades y anuncios", circuló desde el año 1844, aunque en principio con el nombre El Monitor Constitucional. Cambió de nombre en 1846 y circuló hasta el año 1896. Su temática más patente fue la política. Junto con El Siglo XIX y El Ateneo, este diario promulgó la defensa del liberalismo reinante durante los años de la Reforma, en contra de los conservadores y de algunos liberales moderados. Entre sus colaboradores destacan los nombres de Francisco Zarco (1829-1869), Manuel Payno (1810-1894), Guillermo Prieto (1818-1897), José María Vigil (1829-1909), Ignacio Ramírez (1818-1879) y Juan A. Mateos (1831-1913), entre otros. 
recomendó y prestó su amigo, luego continuó con los números ya publicados y finalmente se dio a la espera semanal de los cuadernillos, hasta terminar de leerla ("Bosquejos", El Federalista, 5 de junio de 1871).

Altamirano era considerado por sus contemporáneos como el "Maestro", no hay una mejor definición para él que la del "hombre de letras" decimonónico, es decir, un tipo de intelectual en el que se conjuga el ciudadano ejemplar, el activista político y el "publicista" (el periodista del siglo XIX). En la mayoría de los casos esta persona colaboraba con frecuencia de un órgano de prensa, así como de tertulias y agrupaciones culturales, sobre todo pero no exclusivamente literarias. En el caso de Altamirano, y desde el liberalismo de la época, su participación política y cultural, ambas indisolubles, instaban por el "progreso" de la patria desde la acción mejoradora de la educación. Para ello, el autor resaltó la importancia de la lectura, pero sobre todo de la conformación de instituciones gubernamentales. Políticamente buscó la conformación de grupos culturales, los cuales se encargaban posteriormente de difundir su proyecto ideológico (Brading, 1991). De esta manera Altamirano hizo eco de las cualidades que poseían las manifestaciones culturales, nacionales y extranjeras, pero siempre vinculándolas con la justificación de sus ideas. En este sentido, la lectura que hizo de María no podía separarse de sus ideales, de su afán por llevar a cabo sus proyectos ideológicos liberales.

Decir lo anterior obliga a una apreciación histórica: en el contexto político mexicano es vital comprender, tal como sucedió en muchas naciones americanas, que la Independencia política del país se vio secundada por una serie de batallas en el interior de la nueva nación, incluso, por intentos de reconquista por parte de naciones extranjeras. En el caso de México, después de 1821, fecha que la historiografía ha declarado como año de la Independencia, los liberales se vieron obligados a sostener luchas intestinas con los conservadores en la Revolución de Ayluta (1854) y la Guerra de los Tres Años (1858-1860), y después contra los franceses en un intento de reconquista (1862). Las luchas se sucedieron hasta finales de los años sesenta del siglo XIX, hasta que Benito Juárez (18061872) llegó al poder y empezó a reinar una atmósfera de relativa paz política, condición necesaria para que los proyectos culturales se consolidaran (véase al respecto al mismo Altamirano, 1958, quien como protagonista narra lo sucedido desde su punto de vista, o un análisis posterior, en Sánchez, 1964). En ese momento, la figura de Altamirano jugó un papel fundamental ya que, a diferencia de los anteriores próceres, Altamirano prefirió la pluma a la espada, lo que se verá evidenciado en la conformación de una serie de instituciones culturales en pro de la creación de una "literatura nacional". Es decir, Altamirano necesitó de la estabilidad política y social para poner en marcha sus planes culturales, ideológicos e intelectuales. $\mathrm{Al}$ respecto, el historiador y estudioso de México, David Brading (1991), expone:

\footnotetext{
Mientras que [gnacio] Ramírez [más conocido como "El Nigromante", guía intelectual de Ignacio Manuel Altamirano] era un destacado político, estudioso de la economía política y un mordaz periodista, Altamirano era, antes bien, hombre de letras, de temperamento conciliador, tendente a la nostalgia romántica, quien tenía en su crédito considerables logros literarios. Ambos ejemplificaron el surgimiento, en México, de una nueva clase de intelectuales, que dependían de su cerebro y de sus plumas para rescatarlos de la oscuridad, aunque raras veces de la pobreza. El que hubiesen intervenido en forma tan destacada en la vida pública de su patria demuestra el papel central de la cultura liberal en la política mexicana durante el periodo de Reforma (p. 710. El subrayado es nuestro).
}

Tertulias, organizaciones, institutos de educación, bibliotecas y publicaciones periódicas se sucederán a lo largo de la vida de Altamirano en su rol de mediador cultural, o en su rol de "animador", tal como era 
llamado por sus contemporáneos ${ }^{8}$. En definitiva, se trató de un gestor cultural (o lo que entendemos en términos actuales como tal), avalado y en muchos casos apoyado materialmente por las políticas liberales de su época, un "hombre de letras", como ya se ha dicho, que alentaba a sus contemporáneos a la escritura, edición y lectura crítica de la literatura, al tiempo que él hacía lo mismo; lo que se evidencia en su constante búsqueda de materiales con los que daba testimonio de la necesidad cultural y política de una literatura propiamente mexicana, y en esta búsqueda María jugará un papel central de las ideas de Altamirano?.

Es necesario indicar que para este periodo, bajo las directivas de los liberales, se instó por generalizar la instrucción en todos los niveles sociales, condición necesaria para el proyecto civilista de Altamirano basado en la educación. Las Leyes de la Reforma contemplaban una separación categórica entre la Iglesia y el Estado, estableciendo tres principios básicos de la educación, ésta debía ser laica, gratuita y obligatoria. En este proyecto el positivismo jugó un papel importante, por lo menos en la idea de nación y en la invención de un nuevo tipo de ciudadano: ordenado y respetuoso de la paz. Para 1870 ya se había impreso varios e importantes libros de texto elaborados por autores nacionales, auspiciados por las propias Academias del gobierno. Asimismo, se intentó superar la lectura de memorización por la lectura de comprensión, y se buscó la simultaneidad en la enseñanza de la escritura y la lectura; al tiempo que se apoyaba el surgimiento de una conciencia nacional. Asociaciones e instituciones del Estado intentaron fomentar la instrucción, inspirarles a los ciudadanos sentimientos nobles, ardiente amor por el país, para ser personas de bien, "verdaderos" ciudadanos (Bermúdez, 1988); todas estas acciones permitirán, asimismo, que el proyecto de Altamirano se lleve a cabo positivamente; proyecto en el que interviene la obra de Issacs ${ }^{10}$.

\section{Notas, reseñas, discusiones $y$ prólogos. Reconstrucción de la recepción de María}

La obra de Isaacs logró una serie de referencias, directas e indirectas, en diversos medios periódicos provenientes de la pluma de Altamirano y su grupo de amigos, los intelectuales liberales de la segunda mitad del siglo XIX. En aras de la concisión nos limitaremos a dar cuenta de los textos más sobresalientes publicados por Altamirano. Así, en la nota "Bosquejos", publicada por primera vez el 5 de junio de 1871 en El Federalista, pero luego compilada bajo el título "La literatura en 1870", Altamirano estudió el caso de la novela mexicana. En dicha nota Altamirano advirtió que, a diferencia de las naciones europeas, México no había alcanzado una obra literaria de gran valor, ya que el autor debía enfrentarse con una dura realidad: la falta de un público lector mínimo. Sólo los lectores, dicta Altamirano, garantizan la "popularización" del género y con ellos los recursos materiales suficientes para que al autor se dedique por entero a su arte. Subraya la importancia, en este sentido, de autores tales como Dickens en Inglaterra y Goethe en Alemania, autores que gracias al público lograron vender su obra sin desmejorar su estilo

8 La importancia de Altamirano como "mediador cultural” se explicita en el artículo, próximo a publicarse: "Ignacio Manuel Altamirano (1834-1893): mediador cultural de la vida literaria (México: 1867-1889)" (Bedoya, 2015).

9 Para un acercamiento a Ignacio Manuel Altamirano y sus proyectos culturales, en comparación con el contexto cultural colombiano, véase Bedoya (2012). Este artículo se centra en el proyecto cultural de mayor envergadura del mexicano, su revista $E l$ Renacimiento (1869-1894).

10 La importancia de las instituciones culturales y las publicaciones periódicas en la configuración de un tipo de sociedad ideal, se pueden establecer, igualmente, en el margen conservador de la sociedad mexicana. En la época, los católicos se enfrentaron al liberalismo estableciendo las bases de la civilización cristiana, tanto en la prensa, como en el teatro, las escuelas, las organizaciones laborales, las agrupaciones políticas y las asociaciones de diversos tipos. Los católicos produjeron su propia literatura y sus medios de difusión, para defender y proponer las concepciones cristianas en una sociedad en proceso de secularización (Ceballos, 1988). 
para lograr agradar ${ }^{11}$. Luego llama la atención sobre el caso americano, donde resalta la importancia de María de Isaacs. Según Altamirano, la obra del colombiano logró aquello que él mismo venía buscando para la literatura de su nación: "el ideal del sentimiento americano". Altamirano resalta la importancia que significa que un autor logre la "fama", al tiempo que reconoce el valor artístico de la obra, la cual compara con Dafnis y Cloe, de Longo, y gracias al manejo que hace de la moralidad, Altamirano establece que María es más "alta" que Werther de Goethe, o que Pablo y Virginia, de SaintPierre, todas ellas consideradas obras de alta estima y modelos de conducta para la sociedad mexicana de la época. Para Altamirano, la grandeza de la obra descansa en ser una "novela sentimental", pero perteneciente a la "escuela del realismo", ya que antes que "ficción" es una "historia", una "fotografía" de la realidad americana. En este sentido tenemos que decir que para Altamirano el poder de la novela recae en su idea de "retrato fiel" de la realidad, o para ser más exactos, en su "idealización realista" de la sociedad y en la preservación de todos los valores morales.

En el año 1881 Altamirano preparó la introducción
"María. Novela Americana por Jorge Isaacs", para la edición de la Tipografía Literaria de México. En dicha introducción, Altamirano dijo que nadie en Europa, y ni siquiera el mismo autor colombiano, puede creer la manera en que la novela se convirtió en una "obra maestra" en México y en todo el mundo. Altamirano explica que en su tiempo las obras siempre llegaban de España y de Francia, en la mayoría de las ocasiones "acentuadas" por los anuncios y la publicidad, pero después de algunos días o meses las obras eran olvidadas, ya que no poseían, además de lo novelesco, "una teoría del porvenir atrevida y grandiosa; algo, ciertamente, como un decálogo filosófico o moral". Esta característica que le falta a gran parte de las obras españolas y francesas es justamente la que el mexicano halla en las obras superiores, en este caso, en la obra de Isaacs, pues no es gratuito que la novela del colombiano le recuerde la tragedia griega, sobre todo a Esquilo y Sófocles. En otras palabras, Altamirano rescata de la novela colombiana que todo en ella sea digno de imitar por los jóvenes mexicanos que empiezan a conforman la ciudadanía responsable de su país. Formalmente, dice Altamirano, María es una obra "original", ya que la novela es exacta- mente "americanista", "seductora" y "poética" (recuérdese que es justamente el elemento americanista el que Altamirano busca y recomienda entre sus contemporáneos y discípulos). El mexicano argumenta que la clave de la novela está en conjugar la verdad con el talento, y no en tramas imposibles o sentimientos altamente afectados. De nuevo rastrea los antecedentes de la obra en Pablo y Virginia (Saint-Pierre), Atala (Chateaubriand) y Werther (Goethe). Así, el suicidio poco ejemplar del personaje de Goethe le impide a Altamirano argumentar a favor del alemán. En contraposición piensa que la muerte natural del personaje femenino de Isaacs es más virtuosa y recta. Para Altamirano, en esta ocasión, la obra es "idílica", ya que la misma obra es la personificación de la poesía americana y su naturaleza en todo su "esplendor" descrita. A Altamirano no le interesa en grado sumo el estudio pormenorizado de la obra de Isaacs, lo que le interesa es la alusión directa de las ventajas sociales que conlleva la lectura del colombiano, y la aplicación de la conducta de sus personajes en la sociedad civil de la nación que él, como intelectual, está ayudando a formar. Continúa con las comparaciones y en este caso lo hace con obras del realismo y el naturalismo francés

11 Lo anterior en palabras del propio Altamirano, pues Lewis A. Coser (1968), en el año 1965 establece que aunque Dickens "se esforzaba por conservar su integridad artística" (p. 78), ya que el dinero recibido por sus obras no era un fin sino un medio para lograr la aceptación de su público, fue justamente la cercanía con este último lo que le "impidió hacer, en la mayor parte de su obra, una crítica radical en la sociedad victoriana" (p. 79). 
del siglo XIX: Altamirano plantea que en María no hay nada "abrupto", como en Zola o en el realismo de Daudet y Balzac. Para Altamirano estas obras no son de fiar, por lo menos no como modelos de conducta $^{12}$.

En el año 1883 Altamirano publica una serie de textos, bajo el título "Una polémica con motivo de la "María" de Jorge Isaacs". La polémica fue publicada en El Diario del Hogar, los días 27 de mayo y 3 y 10 de junio de 1883. En este documento por entregas Altamirano comenta, sistemáticamente, las erratas de la edición de la obra publicada en Barcelona, un año atrás. Altamirano lamenta las inconsistencias de dicha edición (un problema de los cajistas que deben "trabajar mucho" y descuidan sus obras), pero sobre todo, lamenta y critica el prólogo que acompaña a la novela, en principio porque está firmado por el desconocido "C. de la K.", el cual se permite enjuiciar la obra sin demostrar ni justificar ninguna de sus ideas. Pero además, se queja porque la obra posee algunos grabados al zinc hechos por Riquer, mientras que Altamirano espera que algún día la obra sea grabada por artistas del talento de Staal, Alfredo Johannot o Doré. Altamirano continúa con su crítica y reproduce el citado prólogo en la publicación periódica. Luego resalta que el desconocido autor haya, primero, recibido con prevención la obra al tratarse de una obra americana ${ }^{13}$.

Volviendo con la crítica de Altamirano al citado prólogo, el mexicano rechaza que el desconocido crítico declare que leyó la obra con la idea, no de disfrutarla, sino de criticarla. Para Altamirano lo anterior es todo un error, pues el juicio del crítico ya estaba contaminado, en sus propias palabras, se trató de un juicio a priori. Luego, Altamirano presenta el recorrido que la novela ha hecho a lo largo de los años. Así, expone que en México ha sido muy bien recibida: él mismo hizo el prólogo de la sexta edición, y después de dicha edición se pueden contar dos más (de la casa editorial de
Mata y de la casa editorial de Dublán). Lo que más le molesta a Altamirano del prólogo de la edición de Barcelona es que su autor dice que alguien ha establecido el paralelo entre la obra de Isaacs y Pablo y Virginia (Saint-Pierre), Atala (Chateaubriand) o Graziella (Lamartine), lo que le parece al crítico europeo sumamente "aventurado". Por obvias razones, Altamirano se siente aludido, así que dedica el resto de su publicación a demostrar sus palabras: para Altamirano la obra de Isaacs es superior a las obras europeas en cuestión, ya que su resorte no es el amor adúltero (como en Werther de Goethe, Clara del Alba de Madame Cottin y Delfina de Madame de Staël), ni tampoco se conforma con la realidad de la vida (como sería el caso de Pablo y Virginia de Saint-Pierre y Atala de Chateaubriand). En comparación con Pablo y Virgina dice que no hay "verdad", en cambio en María sí. Y en comparación con Atala, la obra del colombiano no debe recurrir a un elemento inverosímil, sino a la enfermedad como trama de

12 Finalmente, Altamirano apunta que México cuenta con cinco ediciones de la obra y que su introducción abrirá la sexta, seguro de que habrá muchas más. Indica que se trata de una edición corregida por él mismo, en la que se depura de las imperfecciones de la primera edición que ha servido de copia para las posteriores, para lo cual aclara que solo ha corregido las erratas. Altamirano cuenta que él y Peredo recomendaron la lectura a sus amigos y opositores ideológicos, y que fue esta comunidad lectora la que rescató los méritos de la novela, popularizándola para que ella, por sus propias facultades artísticas, lograra la admiración del público.

13 Lo anterior le da pie a Altamirano para quejarse de la actitud de los europeos, sobre todo de los españoles, que han menospreciado las producciones americanas. Altamirano recapitula la tradición literaria americana, fundada por autores tan importantes en su consideración como Bello y Olmedo. Incluso establece que tales nombres, junto con el de Isaacs, demuestran que América ya posee una literatura propia por encima de la América sajona, en donde algunos críticos norteamericanos han reconocido que no tienen, por ejemplo, "un cuadro social más lleno de color que la Amalia de Mármol, ni una novela más llena de sentimientos que la María de Jorge Isaacs”. Sin embargo, continúa Altamirano, el desconocimiento de la grandeza literaria americana en Europa se debe a la falta de publicidad de los libros americanos en España, incluso en la misma América, pues tan sólo se pueden editar materiales de pocos ejemplares que no alcanzan una segunda edición. Además, continúa Altamirano, el público lector americano es muy pequeño, y por todo lo anterior, es más fácil conocer lo europeo que lo propio. 
su obra. Al fin y al cabo, es la verdad lo que inspira las obras de arte. De nuevo, Altamirano alude a razones morales, de comportamiento, más que literarias, para justificar la obra del colombiano, sobre las obras de los autores europeos. De esta manera intenta "inspirar" a los nóveles escritores a publicar, tal como lo hizo Isaacs, pero desde unos parámetros nacionales, incluso americanos si se quiere, pero no extranjeros europeos o anglosajones. La idea de Altamirano es formar a los lectores, pero también a los escritores (formarlos en términos literarios, pero también de comportamiento civil), sirviéndose del ejemplo de Isaacs y de los personajes de su novela.

En "Honra y provecho de un autor de libros en México", publicado en El Diario del Hogar el 29 de abril de 1887 , Altamirano cuenta la historia de uno de sus amigos, que ante la precaria realidad cultural de su país termina perdiendo dinero con la publicación de su obra. ${ }^{14}$ Sin embargo, Altamirano rescata la importancia y el ejemplo de la obra del colombiano, que para la época, según sus propias palabras, ya había coleccionado cinco ediciones en México, de modo que podía darse el gusto de vivir de su escritura; la idea aquí es clara para los jóvenes escritores mexicanos: se puede vivir de la escritura, si se conjuga moralidad con literatura nacional, esto es, un tema nacional, ademásde maestría en el ejercicio estético.

El afecto de Altamirano por la obra de Isaacs desemboca en la creación de una edición guiada por las directrices de Altamirano, pero ejecutada por sus discípulos, pues la edición tan sólo fue publicada en el año 1898 en París (cinco años después de la muerte de Altamirano), en la prestigiosa Casa Editorial Garnier Hermanos. La edición de 432 páginas abre con el Prólogo de José María Vergara y Vergara (1831-1872), firmado en Bogotá en el mes de junio de 1867, es decir, el prólogo de la primera edición de la novela ${ }^{15}$. Después del prólogo del colombiano la edición presenta la obra de Isaacs, antecedida de la dedicatoria: "A los hermanos de Efraín", que Issacs sumó a la segunda edición de su novela ${ }^{16}$. Le sigue a la edición un "Vocabulario de los provincialismos más notables que ocurren en esta obra", identificando los propios del Cauca y los de Antioquia (1867, pp. 407- 410). Por último, la edición cierra con una serie de juicios críticos escritos por Altamirano y sus discípulos: Guillermo Prieto (1818 - 1897) y Justo Sierra (1848-1912).

En esta edición los alumnos de Altamirano publican el texto crítico de su maestro, en el que Altamirano ratifica la importancia de la obra sobre las novelas europeas, al grado de declarar: "Yo creo que María es superior a la obra de Chateaubriand" (p. 417). En esa misma línea se encuentra el texto de Guillermo Prieto, titulado igual que el de su maestro: "María, novela americana por Jorge Isaacs", en el que el joven autor expone las cualidades de la obra, para concluir:

14 En el texto se da noticia de cómo una editorial paga al autor cinco pesos por la escritura de un ensayo, cuya venta producirá cinco mil pesos. Es decir, la editorial solo le paga al autor el $0.5 \%$ de la venta de su libro. De esta manera, concluye Altamirano, escribir libros no es un "negocio".

15 Vergara y Vergara fue el fundador de la tertulia El Mosaico, que acogió a Isaacs en la capital, al tiempo que fue la persona responsable de la difusión de la vida literaria colombiana de mediados del siglo XIX colombiano. Guardadas las diferencias, Vergara y Vergara, de formación y creencia conservadora, es considerado el promotor cultural de la Nueva Granada tal como Altamirano lo era para México.

16 Dedicatoria que, a manera de juego literario, da a entender la existencia de Efraín, María y el resto de personajes. Recuérdese que la novela está antecedida de una nota en la que un narrador externo, el propio Isaacs, cuenta que los papeles que componen la novela, escrita por Efraín, le fueron puestos en sus manos para su edición y publicación. De esta manera, la función de la novela como historia que realmente había sucedido se patentaba desde el inicio, a ello se deben sumar las anécdotas del propio Isaacs, quien había mandado pintar un cuadro de su personaje femenino, cuadro que colgó en su hacienda, la misma en la que, se supone, sucedieron los hechos ( $\mathrm{y}$ que incluso en la actualidad la gente visita como si se tratara de un hecho y no de una ficción literaria). 
Yo, al inclinarme sobre este libro, que así le llamaré porque mi lengua torpe no alcanza epíteto más expresivo, he sentido la magia de una aparición, y como vencido el retrotraimiento (sic) del tiempo: allí estaba yo, ése es el libro mío; ¿por qué no me es dado escribir así? (p. 419).

Y por último, se publica el texto del joven Justo Sierra, quien es considerado uno de los autores encargados de continuar, desde el ideario liberal, con la tarea del ya viejo Altamirano. Su texto: "María, impresiones de un libro de Jorge Isaacs" está dedicado a su maestro. En su juicio, Sierra expone:

Quizá la impresión que ha hecho en el mundo hispano-americano el libro admirable de Jorge Isaacs, proviene de los recuerdos que hemos sentido de mejores días: hay en el desierto de nuestros corazones, perdidas allá en la sombra, las ruinas sagradas de un templo, del santuario inmaculado de nuestras ilusiones, en donde ardía, lámpara purísima, el culto del sentimiento (p. 423).

Es justamente el tiempo pasado, el que ya no pertenece a la influencia de Altamirano, el que extraña el joven Sierra. Su maestro ya no los acompaña, ya son otras circunstancias so- ciales las que acompañan a los intelectuales, asimismo, otro tipo de consideraciones culturales, literarias. Por encima del recuerdo de Altamirano, se levantan los nombres de jóvenes figuras que empiezan a establecer sus diferencias con el maestro. En este sentido, la obra de Isaacs cobra un valor distinto para los mexicanos de finales del siglo XIX, mientras que para Altamirano y su grupo de letrados la obra debía ser rescatada, promocionada, pero sobre todo, imitada: ya fuera en su aspecto anecdótico (contar una historia americana con personajes que sirvieran de modelos de comportamiento), como en su aspecto literario (una obra bella y original, y eso significaba americana) y también, como ejemplo profesional para los jóvenes intelectuales de la época (poder vivir de la escritura y hacerse un nombre).

\section{Conclusiones}

El acercamiento crítico que Altamirano realizó de las obras literarias extranjeras tenía una meta expresa: nutrir la literatura mexicana. La novela de Isaacs le permitió justificar sus ideas en torno a la literatura, pero también en torno a la sociedad y al proyecto de nación. De María le interesó sobremanera el color local, americano, la descripción detallada de la realidad, o de una supuesta realidad nacional. Pero sobre todo, le interesó porque no era europea, porque tampoco era obscena ni inmoral. La figura de Isaacs le permitió demostrar su idea de que sí era posible formar escritores en América, pero no cualquier tipo de escritor, sino un "verdadero" escritor, reconocido por su labor, "famoso", avalado por su público lector, que no se viera obligado a sacrificar su arte por el reconocimiento, el escritor cuyo parangón europeo había sidotipo Goethe y Dickens. Dado lo anterior, Altamirano no se cansa de comparar a Isaacs con el maestro alemán. En términos de Altamirano, la obra de Isaacs redunda en utilidad, belleza, pero sobre todo moralidad. Su idea sobre la importancia de María será heredada por sus discípulos. Recuérdese, por ejemplo, uno de los proyectos culturales de mayor importancia en México, la revista literaria El Renacimiento, dirigida por Altamirano ${ }^{17}$. Este órgano periódico será continuado también por los discípulos de Altamirano, y en su segunda época, hombres como Justo Sierra o Manuel Gutiérrez Nájera (1859-1895) continuarán su legado.

En el caso de Gutiérrez Nájera, éste, desde las improntas modernistas, aludirá a

17 La cual, a manera de prospecto dictaba: "Con el objeto, pues, de que haya en la capital de la República un órgano de estos trabajos, un foco de entusiasmo y de animación para la juventud estudiosa de México, hemos fundado este periódico”. 
la importancia de la novela en los mismos términos descritos por Altamirano, pero ahora haciendo hincapié en las omisiones de la obra, en sus inconsistencias, incluso, atreviéndose a criticarla y desvirtuar un poco su valor real, por lo menos en sus términos dictados por la lectura de autores franceses de mediados y finales del siglo XIX. De ahí, entonces, que narre que no volvió a leer a Isaacs porque tal autor forma parte de su pasado (el mismo al que aludía Sierra), de una lectura de su adolescencia, y tan sólo volverá a ella cuando tenga un hijo, igual que a los cuentos de Dickens (otro de los autores ejemplares para Altamirano). En cambio, lee con pasión otros autores "trascendentales" en su formación, autores que para Altamirano no poseían la impronta literaria:

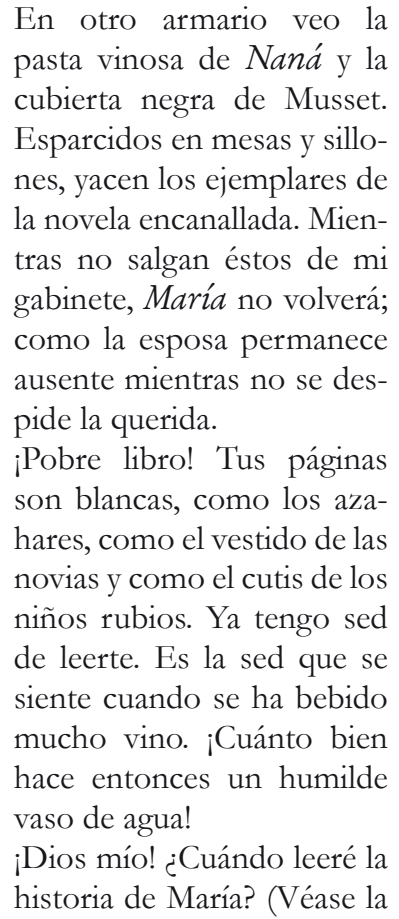

En otro armario veo la pasta vinosa de Naná y la cubierta negra de Musset. Esparcidos en mesas y sillones, yacen los ejemplares de la novela encanallada. Mientras no salgan éstos de mi gabinete, María no volverá; como la esposa permanece ausente mientras no se despide la querida.

¡Pobre libro! Tus páginas son blancas, como los azahares, como el vestido de las novias y como el cutis de los niños rubios. Ya tengo sed de leerte. Es la sed que se siente cuando se ha bebido mucho vino. ¡Cuánto bien hace entonces un humilde vaso de agua!

¡Dios mío! ¿Cuándo leeré la historia de María? (Véase la

nota "Con pretexto de $M a$ ría", escrita por Gutiérrez Nájera en: La Libertad, 23 de noviembre de 1882).

Al final de este texto del joven Gutiérrez Nájera se explicita que su participación fue publicada, en principio, como prólogo a la edición de la obra por la editorial Dublán, en 1882, con el título "Una edición mexicana de María", edición de la cual Altamirano mismo habló en repetidas ocasiones. Por supuesto, la lectura que Gutiérrez Nájera realizó de la obra de Isaacs corresponde a otro tipo de recepción, ahora desde el modernismo y no desde el romanticismo liberal de Altamirano, pero esto es tema de otro artículo y no del presente.

\section{Referencias}

Altamirano, I. M. (1958). Historia y política de México (1821-1882). México: Empresas Editoriales.

Alzate, C. (2012). Encuentros del cine y la literatura en Colombia. Recuento histórico y filmografía total de adaptaciones 1899-2012. Medellín: Ministerio de Cultura, Borealia Libros y Verdades.

Bedoya, G. A. (2015). "Ignacio Manuel Altamirano (1834-1893): mediador cultural de la vida literaria (México: 1867-1889)". Anales de Literatura Hispanoamericana. Madrid (España): Universidad Complutense de Madrid, No 44.

Bedoya, G. A. (2012). "Origen y límites del crítico en dos publicaciones periódicas literarias. El Renacimiento (México: 1869-1894) y El Nuevo Tiempo Literario (Colombia: 1903-1915, 1927-1929)”. Acta Literaria. Concepción (Chile): Departamento de Español. Facultad de Humanidades y Arte. Universidad de Concepción, No 44. p. 135-151.

Bermúdez, M. T. (1988). “Las leyes, los libros de texto y la lectura, 1857-1876”. Historia de la lectura en México. Seminario de historia de la educación en México. México: Centro de Estudios Históricos, El Colegio de México, Ediciones el Ermitaño, pp. 127-152. 
Botero, Á. P. (1999). La fábula y el desastre. Estudios críticos sobre la novela colombiana 1850-1931. Medellín: Fondo Editorial EAFIT.

Brading, D. (1991). Orbe Indiano. De la monarquía católica a la República criolla 1492-1867. México: Fondo de Cultura Económica.

Ceballos, M. (1988). "Las lecturas católicas: cincuenta años de literatura paralela, 1867-1917”. Historia de la lectura en México. Seminario de historia de la educación en México. México: Centro de Estudios Históricos, El Colegio de México, Ediciones el Ermitaño, pp. 153-204.

Coser, L. (1968). Hombres de ideas. El punto de vista de un sociólogo. México: Fondo de Cultura Económica.

Chartier, R. (1994). El orden de los libros. Barcelona: Gedisa Editorial.

Henríquez, P. (1994). Las corrientes literarias en la América Hispánica. Bogotá: Fondo de Cultura Económica.

Isaacs, J. (1898). María. Novela Americana. Con un prólogo de J. M. Vergara y Vergara y juicios de Ignacio M. Altamirano, Guillermo Prieto y Justo Sierra. Nueva Edición. París: Casa Editorial Garnier Hermanos.

Isaacs, J. (1978), María. Prólogo, notas y cronología de Gustavo Mejía. Caracas: Biblioteca Ayacucho.

Jauss, H. R. (2000). La historia de la literatura como provocación. Barcelona: Península, 1967.

Ladrón de Guevara, P. (1998). Novelistas malos y buenos. Juzgados en orden de naciones. Bogotá, Planeta.

Menton, S. (1978). La novela colombiana: planetas y satélites. Bogotá: Plaza y Janés.

Perus, F. (1998). De selvas y selváticos. Ficción autobiográfica y poética narrativa en Jorge Isaacs y José Eustasio Rivera. Bogotá: Plaza \& Janés Editores.

Rincón, C. (2007). "Sobre la recepción de María en Colombia. Crisis de la lectura repetida y pérdida de autoridad del canon (1938-1968)". Memorias del primer simposio internacional Jorge Isaacs. El creador en todas sus facetas. Cali: Editorial Universidad del Valle, pp. 79-110.

Sánchez, A. (1964). Altamirano como militar. México: s.e.

Toro, D. y Vallejo, O. (2007). "Jorge Isaacs en la historiografía literaria colombiana o de cómo se hace un canon”. Memorias del primer simposio internacional Jorge Isaacs. El creador en todas sus facetas. Cali: Editorial Universidad del Valle, pp. 111-120.

Vallejo, F. (1995). Almas en pena chapolas negras. Bogotá: Alfaguara. 